\title{
Hot Ductility of Severe Plastic Deformed AA6061 Aluminum Alloy
}

\author{
Ali Akbar Khamei · Kamran Dehghani
}

Received: 11 July 2014/Revised: 1 October 2014/Published online: 8 January 2015

(c) The Chinese Society for Metals and Springer-Verlag Berlin Heidelberg 2015

\begin{abstract}
The hot ductility of 6061 aluminum alloy, which was subjected to two different severe plastic deformations (SPD), was studied at different temperatures and strain rates. The tensile tests were carried out at the temperature range of $300-500{ }^{\circ} \mathrm{C}$ and at the strain rates of $0.0005-0.01 \mathrm{~s}^{-1}$. The microstructure evolution was characterized using optical microscopy, transmission electron microscopy and X-ray diffraction technique. The influences of the microstructure after SPD, thermomechanical parameters (temperature and strain rate) and specimen size on the hot formability of this alloy were then analyzed. The results show that a decrease in grains/subgrains exhibited significant effect on the hot ductility of SPDed samples. The constitutive equations were then developed to model the hot formability of the studied alloy. The developed model can be represented by Zener-Hollomon parameter in a hyperbolic sinusoidal equation form. Both the changes of elongation to failure and Zener-Hollomon parameter indicate that the hot ductility of the alloy is more sensitive to the temperature rather than to the strain rate. The uniform elongation is independent of the specimen size, but the postnecking elongation increases dramatically as the ratio of $l / A^{1 / 2}$ decreases.
\end{abstract}

\section{KEY WORDS: Al-Mg-Si alloy; Deformation behavior; Equal channel angular pressing (ECAP); Rolling; Hot tensile deformation}

\section{Introduction}

It has been demonstrated that various methods of severe plastic deformation (SPD) can be successfully applied for the grain refinement of AA6061 alloy [1,2]. The SPD can be employed using different techniques; however, the combination of the SPD methods can lead to the enhancement of the mechanical properties. According to the work of Stepanov et al. [3], the combination of equal channel angular pressing (ECAP) and cold rolling (CR) is the most promising approach in terms of industrial

Available online at http://link.springer.com/journal/40195

A. A. Khamei · K. Dehghani $(\bowtie)$

Mining and Metallurgical Engineering Department, Amirkabir

University of Technology, 15914 Tehran, Iran

e-mail: dehghani@aut.ac.ir application to produce sheets with ultra-fine grains (UFG). One concern in this regard is the amount of ductility that can be achieved. For the materials subjected to SPD, attaining a desirable superplasticity at room temperature is not an easy task. Nevertheless, under some conditions, it is possible to achieve very high elongations without the development of any significant localized necking. The fundamental requirements required to achieve superplasticity are well established [4]. The foremost of these are: (1) testing temperature [5] and strain rate [6]; (2) the microstructural characteristics such as small grain size [7] typically smaller than $10 \mu \mathrm{m}$ [8], high stability and uniformity of the grain structure, low dislocation density in grain interiors, large proportion of high-angle grain boundaries [9], second-phase characteristics [10]; and (3) the chemical composition, e.g., the addition of zirconium and scandium to $\mathrm{Al}$ alloys. Also, it is reported that the amount of elongation depends on the size of tensile 
Table 1 Main parameters on superplastic behavior of 6000 Al alloys

\begin{tabular}{lll}
\hline Alloy & Parameter & Max. elongation, temperature, strain rate \\
\hline $6061[15,16]$ & Alloying elements additions $(\mathrm{Cu}, \mathrm{Zr})$ & $1,300 \%, 590{ }^{\circ} \mathrm{C}, 2.8 \times 10^{-4} \mathrm{~s}-1$ \\
$6061[17]$ & Grain refinement (ECAP) & $150 \%, 300{ }^{\circ} \mathrm{C}, 1 \times 10^{-4} \mathrm{~s}^{-1}$ \\
$6061[17]$ & Alloying elements additions (Mg, Zr) & $600 \%, 300{ }^{\circ} \mathrm{C}, 1 \times 10^{-2} \mathrm{~s}^{-1}$ \\
& Grain refinement (HPT) & $375 \%, 540{ }^{\circ} \mathrm{C}, 5 \times 10^{-4} \mathrm{~s}-1$ \\
$6013[18,19]$ & Grain refinement (thermomechanical processing) & \\
$6061[20]$ & Second phase (over aging) & $185 \%, 250{ }^{\circ} \mathrm{C}, 9.15 \times 10^{-4} \mathrm{~s}-1$ \\
$6082[21]$ & Initial structure (Furnace/Water cooling) & \\
$6061[22]$ & Grain refinement (high-ratio differential speed rolling) & $135 \%, 350{ }^{\circ} \mathrm{C}, 1 \times 10^{-3} \mathrm{~s}-1$ \\
$6061[23]$ & Grain refinement (ECAP) & $100 \%, 250{ }^{\circ} \mathrm{C}, 1 \times 10^{-3} \mathrm{~s}^{-1}$ \\
$6061[24]$ & Grain refinement (ECAP) & $115 \%, 300{ }^{\circ} \mathrm{C}, 1 \times 10^{-4} \mathrm{~s}^{-1}$ \\
& Grain refinement (multi-axial compressions/forging) & $280 \%, 540{ }^{\circ} \mathrm{C}, 3 \times 10^{-4} \mathrm{~s}{ }^{-1}$ \\
\hline
\end{tabular}

Table 2 The composition of studied AA6061 (wt\%)

\begin{tabular}{llllllll}
\hline Sample & $\mathrm{Si}$ & $\mathrm{Fe}$ & $\mathrm{Cu}$ & $\mathrm{Mn}$ & $\mathrm{Mg}$ & $\mathrm{Cr}$ & $\mathrm{Al}$ \\
\hline WC & 0.73 & 0.37 & 0.2 & 0.07 & 0.9 & 0.19 & Bal. \\
Standard [25] & $0.4-0.8$ & $\geq 0.7$ & $0.15-0.4$ & $\geq 0.15$ & $0.8-1.2$ & $0.04-0.35$ & Bal. \\
\hline
\end{tabular}

samples [11]. When the tensile specimens, especially in case of UFGed materials, deviate from the sizes and geometries dictated by ASTM standards [12-14], the ductility varies with the gauge length. As shown in Table 1, the effects of different parameters on the superplastic behavior of 6000 aluminum alloys have been studied by many researchers. According to Table 1, although there are limited reports on the hot deformation behavior of AA6061 alloy processed by SPD, there is no report regarding the effects of different parameters on the hot ductility of this alloy after applying two SPD techniques. Therefore, the aim of present work was to study the effects of microstructure development, hot tensile test parameters (strain, strain rate and temperature) and size of tensile sample on the hot deformation behavior of $6061 \mathrm{Al}$ alloy.

\section{Materials and Methods}

The material used in this study was AA6061-T6 alloy with the composition mentioned in Table 2. The ECAP specimens, prepared from the as-received plate, had the dimensions of about $100 \mathrm{~mm} \times 100 \mathrm{~mm} \times 14 \mathrm{~mm}$. They were solutions treated at $803 \mathrm{~K}$ for $4 \mathrm{~h}$ followed by rapid quenching into ice water. The two SPD processes were performed by one and two passes of ECAP followed by
90\% reduction in CR. Both the ECAP and CR were performed at room temperature. The ECAP die configurations (Fig. 1) and the effective strain applied by ECAP (shear) and rolling (true) are shown in Table 3. After applying the ECAP + CR, the final thickness of UFGed sheet was about $1.5 \mathrm{~mm}$, as shown in Fig. 2. Hot tensile tests were performed at temperatures of $573 \mathrm{~K}\left(300{ }^{\circ} \mathrm{C}\right), 673 \mathrm{~K}\left(400{ }^{\circ} \mathrm{C}\right)$ and $773 \mathrm{~K}\left(500{ }^{\circ} \mathrm{C}\right)$ and at the initial strain rates between $1.0 \times 10^{-2}$ and $5.0 \times 10^{-4} \mathrm{~s}^{-1}$. To study the effect of the sample size on the hot ductility of SPDed AA6061, two different samples were investigated, large sample: $31 \mathrm{~mm} \times 6 \mathrm{~mm} \times 1.5 \mathrm{~mm}$ and small sample: $5 \mathrm{~mm}$ $\times 4 \mathrm{~mm} \times 1.5 \mathrm{~mm}$. The microstructural evolutions were characterized using X-ray diffraction (XRD) technique, optical microscopy (OM) and transmission electron microscopy (TEM) operating at $200 \mathrm{kV}$.

\section{Results}

\subsection{Microstructure Development}

\subsubsection{TEM and OM Analysis}

Figure 3a, b shows the TEM images taken from the CRed only and the 2P-ECAPed plus CRed samples, respectively. Figure $3 \mathrm{a}$ presents a heterogeneous structure having some 


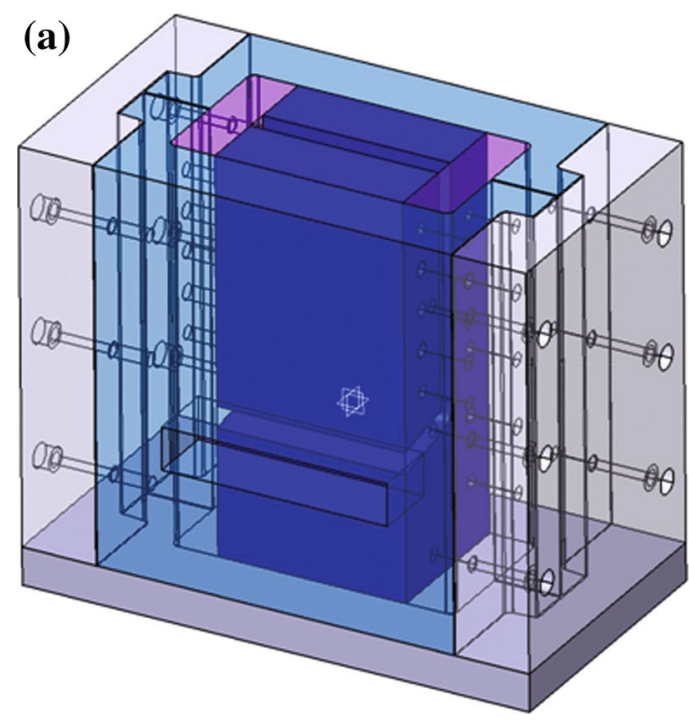

Fig. 1 Design a and production $\mathbf{b}$ of ECAP die

Table 3 Severe plastic deformation parameters (ECAP and rolling)

\begin{tabular}{llllll}
\hline $\begin{array}{l}\text { Channel } \\
\text { angle } \Phi\left({ }^{\circ}\right)\end{array}$ & Route & $\varepsilon$ (shear) & $\begin{array}{l}\text { Pass number } \\
\text { of ECAP }\end{array}$ & $\varepsilon$ (true) & $\varepsilon$ (total) \\
\hline 100 & \multirow{2}{*}{$C_{x}$} & 0.82 & 1 & 2.2 & 3.02 \\
& & 2 & & 3.84 \\
\hline
\end{tabular}

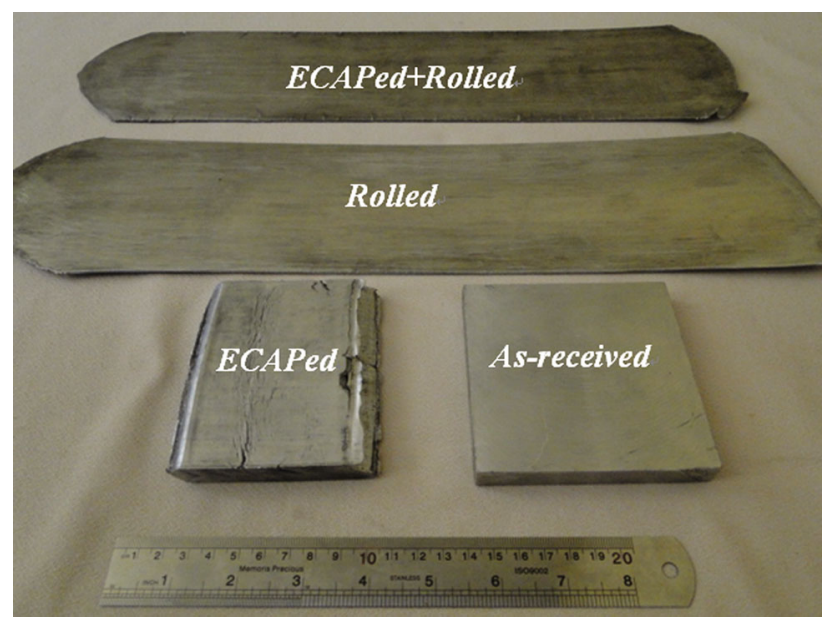

Fig. 2 Production severe plastic deformed $6061 \mathrm{Al}$ alloy in different conditions and shapes

microbands elongated in the rolling direction. As observed in Fig. 3b, the combination of ECAP and subsequent cold rolling can lead to the formation of more homogeneous grains comparing to that of CRed only. Comparing Fig. 3a, $\mathrm{b}$, the grain/subgrain formed in the ECAP plus CRed sample is more distinctive than in case of CRed sample, presumably due to applying higher plastic strain. Also,

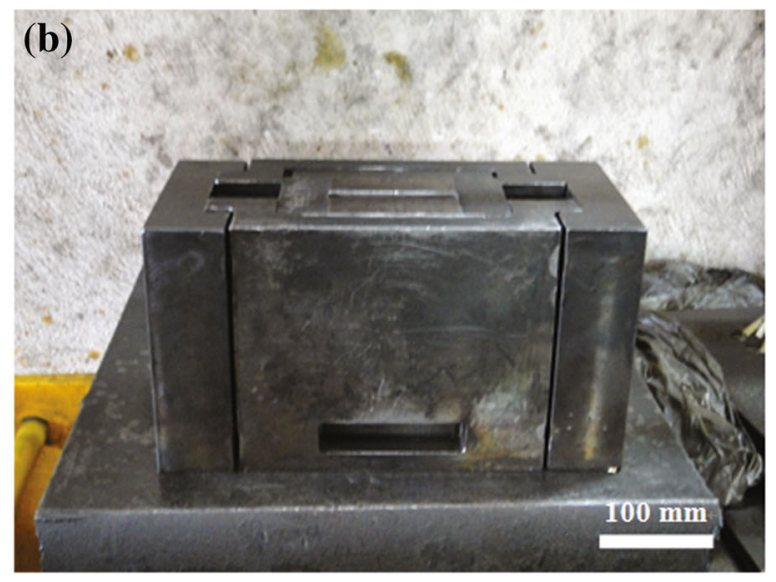

Fig. 4 compares the microstructures obtained at different steps of present work. These are pertaining to the grain sizes after water quench, after cold rolling and after two passes of ECAP plus cold rolling.

\subsubsection{X-ray Diffraction Analysis}

The X-ray diffraction (XRD) patterns regarding the undeformed and deformed samples are shown in Fig. 5. According to the XRD results, four trends can be seen. First, the peak of the (200) plane is dominant for the ECAPed + CRed samples. The maximum peak intensity of undeformed sample is pertaining to the (111) plane. The intensity of both planes regarding the CRed and ECAPed + CRed cases is almost identical. This can be due to the formation of different textures during the ECAP and CR processes [26]. Second, the (111) peak for the asreceived sample has the highest intensity; whereas those concerning the CRed and ECAP + CRed samples have lower intensity. This drastic reduction in the intensity can be because of higher strains applied during SPD techniques [27]. Third, the broadening of the peaks (FWHM, full width half maximum) is different for different processed samples. For example, on two planes, the maximum value of the peak broadening is pertaining to the CRed and ECAPed + CRed samples. The changes in peak width can be attributed to the increase in dislocation densities [26, 28], formation of UFGs [26], development of fine subgrains, development of internal strain (residual stress) [29] and higher lattice distortion [30]. In this regard, Nan $\mathrm{Li}$ et al. [31] used XRD analysis to study the residual stresses generated during SPD. Fourth, referring to Fig. 5b, with increasing the imposed strain during ECAP or by 

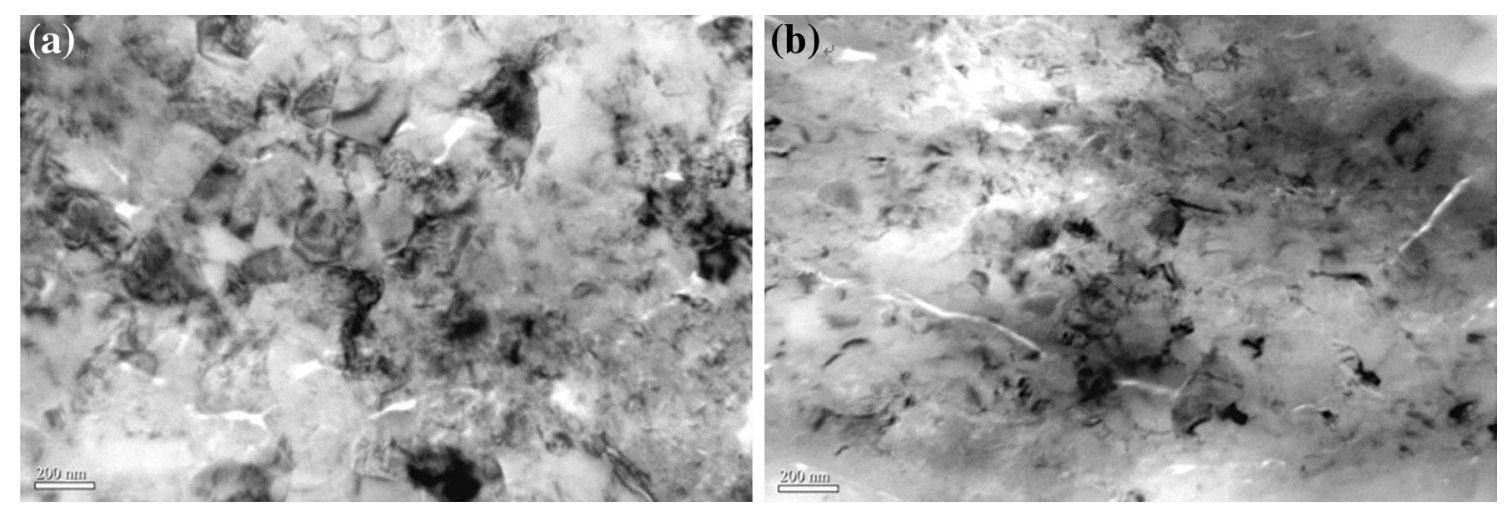

Fig. 3 TEM images of the deformed samples after cold rolling a, 2-pass ECAP plus cold rolling $\mathbf{b}$
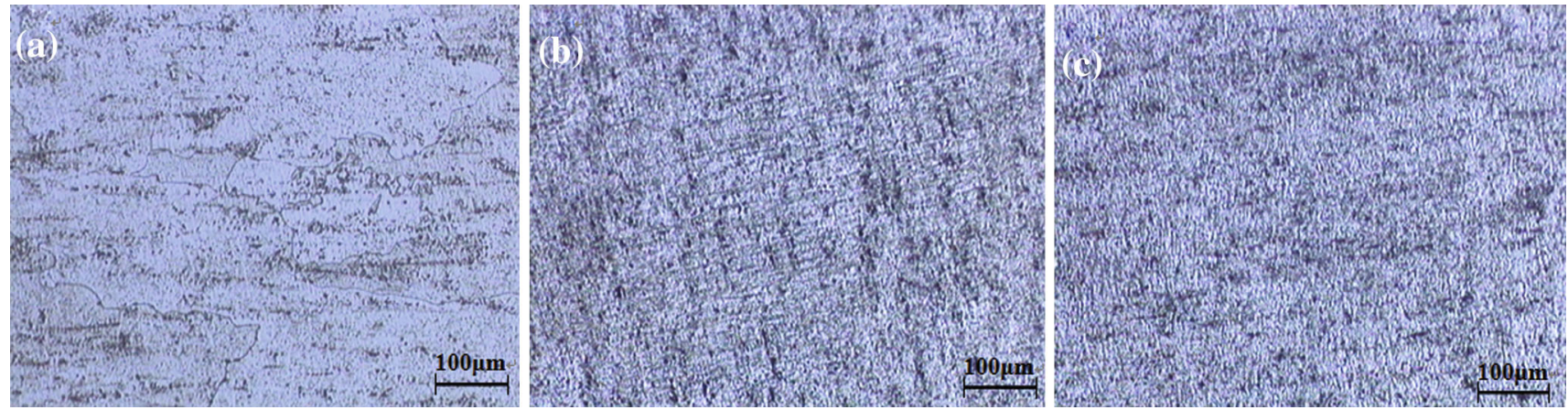

Fig. 4 OM microstructures of 6061 alloy: a after water quench, b after cold rolling, $\mathbf{c}$ after two passes of ECAP plus cold rolling
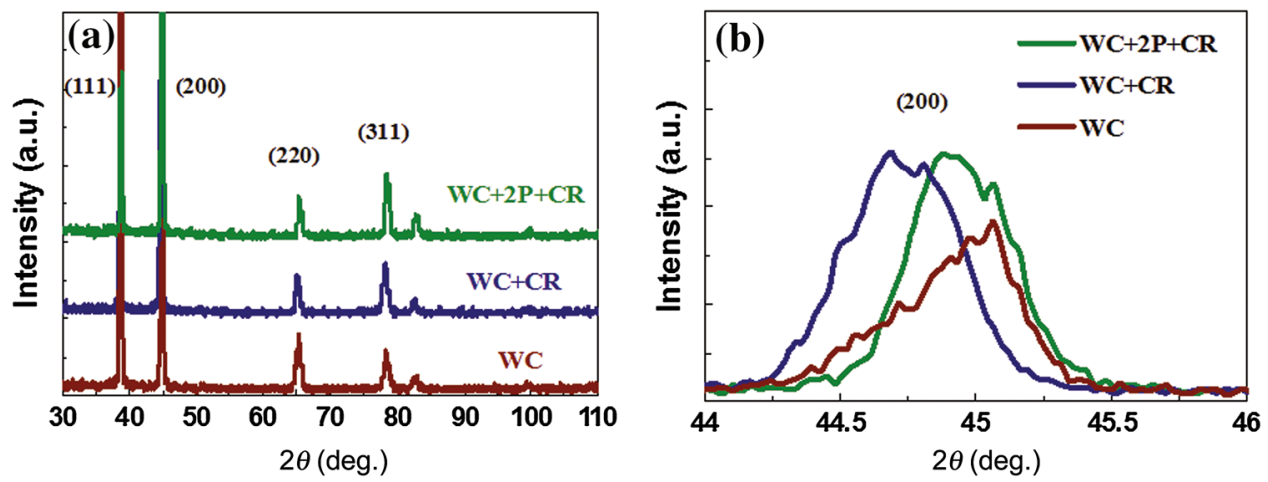

Fig. 5 XRD patterns of the alloy under different conditions: a all planes, b (200) plane

applying subsequent rolling process after ECAP, the peaks are shifted to lower degrees. It can be concluded that the shift in the peak is probably due to the higher plastic strains or severe plastic deformation.

\subsection{Hot Ductility Behavior}

\subsubsection{True Stress-True Strain Curves}

The typical true stress-true strain curves of the SPDed AA6061 alloy obtained at different temperatures and strain rates are shown in Fig. 6. As expected, the flow stress of the alloy is a strong function of the temperature and the strain rate. Figure 7 indicates the influence strain rate and temperature on the elongation of the SPDed alloy. It can be observed from Fig. 7a that the dependence of the ductility on the strain rate differs considerably depending on the amount of temperature. Although the elongation of $55 \%$ was achieved at the lowest strain rate of $0.0005 \mathrm{~s}^{-1}$ at $300{ }^{\circ} \mathrm{C}$, it increased to about $88 \%$ for the specimen tested at $0.01 \mathrm{~s}^{-1}$ and $500{ }^{\circ} \mathrm{C}$. For example, at the temperature of $300{ }^{\circ} \mathrm{C}$, the ductility decreases continuously with increasing the strain rate. Besides, it can be seen from Fig. 7a that when the deformation temperature is increased, the peak strain decreases to a maximum followed by a decrease. In the other words, with increasing the temperature to $400{ }^{\circ} \mathrm{C}$, 

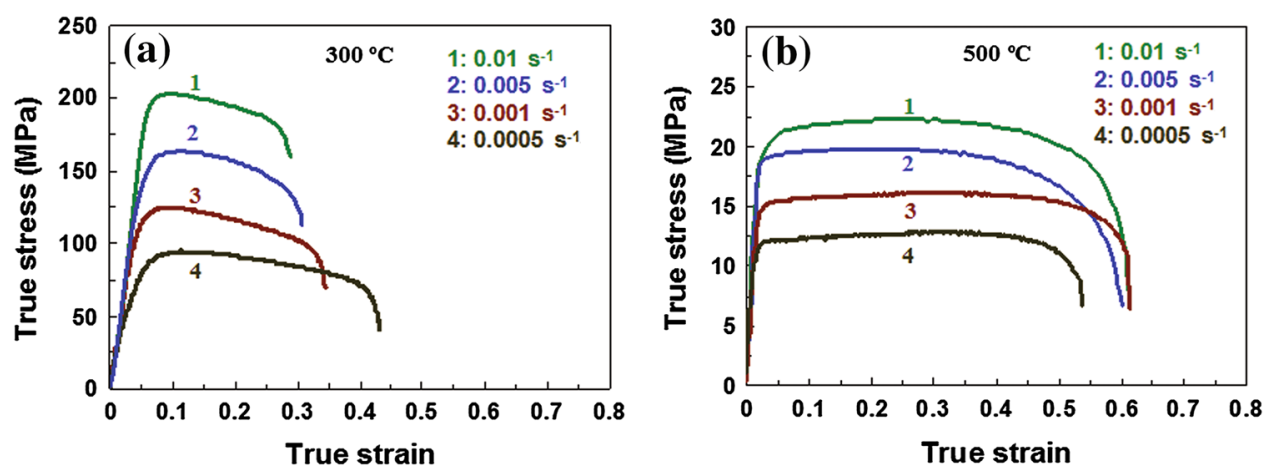

Fig. 6 Typical true stress-strain curves for WC $+2 \mathrm{P}($ ECAP $)+$ CRed 6061 alloy under the different strain rates and deformation temperatures of $300{ }^{\circ} \mathrm{C}$ a, $500{ }^{\circ} \mathrm{C} \mathrm{b}$
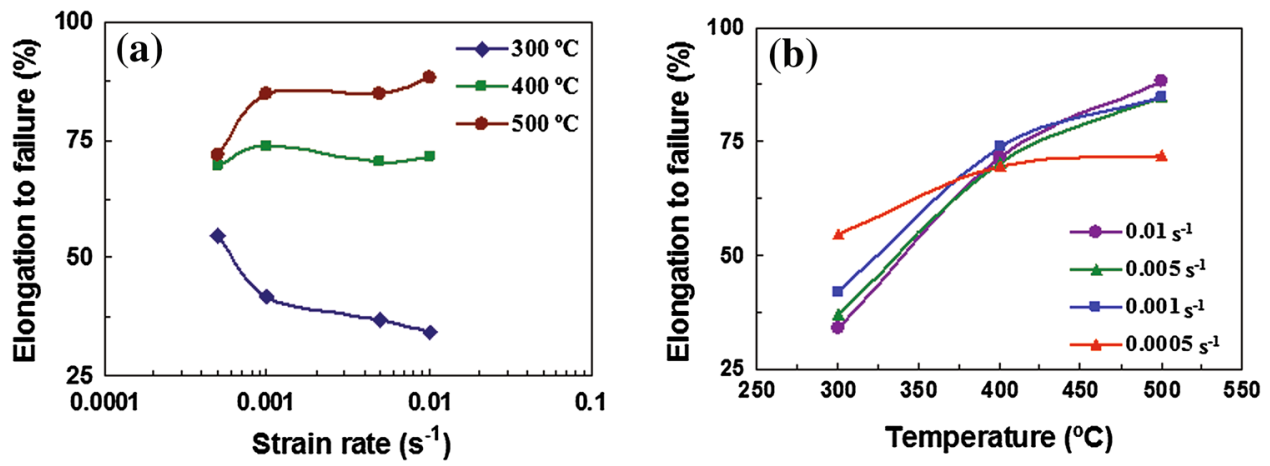

Fig. 7 Effects of strain rate a, deformation temperature $\mathbf{b}$ on the hot ductility of WC $+2 \mathrm{P}(\mathrm{ECAP})+$ CRed 6061 alloy
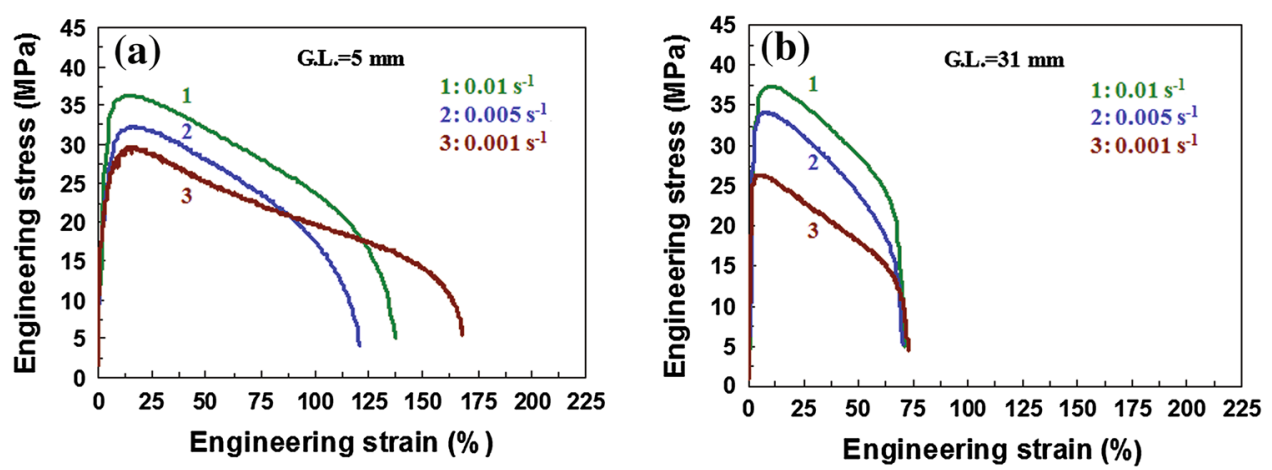

Fig. 8 Flow stress versus elongation to failure over a range of strain rates at $400{ }^{\circ} \mathrm{C}$ for severe plastic deformed samples: a WC $+1 \mathrm{P}$ $($ ECAP $)+$ CRed, $\mathbf{b}$ WC $+2 \mathrm{P}($ ECAP $)+$ CRed

the elongation is increased reaching to a maximum at the strain rate of $0.001 \mathrm{~s}^{-1}$. According to Fig. 7b, the elongation rises continuously with increasing the temperature.

\subsubsection{Tensile Tests with Different Sample Sizes}

To study the effect of the gauge length on the hot ductility, the typical plots of the flow stress versus elongation were obtained for the samples subjected to different SPDs, shown in Fig. 8. The samples were pulled to failure at $400{ }^{\circ} \mathrm{C}$. It can be observed that in the first stage of deformation, the flow stress increases quickly with strain exhibiting a high work-hardening rate. The most important step in hot tensile test is region after the UTS peak, socalled post-uniform elongation occurred after necking. This is normally accompanied by a drop in flow stress.

\section{Discussion}

4.1 Effect of the Microstructure on the Hot Ductility

According to the results of XRD, OM and TEM, the combination of two different SPD methods leads to a 


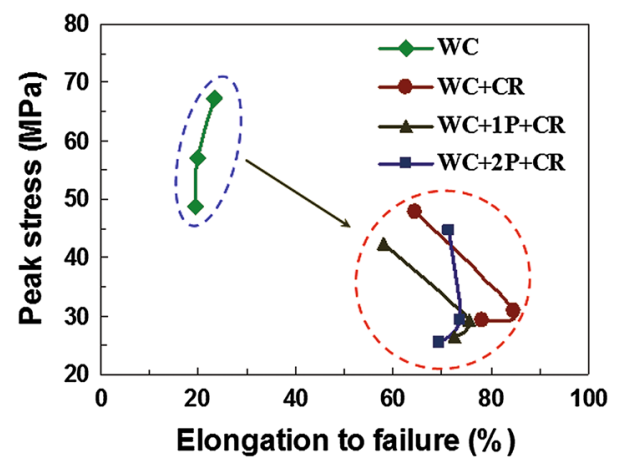

Fig. 9 Variation of the peak stress versus the elongation percent at $400{ }^{\circ} \mathrm{C}$ and different strain rates

decrease in grain/subgrain size and in higher dislocation density (increasing the peak width). In other words, during the SPD processes, the grain/subgrain size was decreased compared to the undeformed samples due to applying the high plastic strains. It is reported [32] that when the pure Ti was subjected to ECAP followed by drawing process, a considerable decrease in grain/subgrain size was observed comparing to applying only ECAP process. Also, employing the $\mathrm{CR}$ after the ECAP led to significant increase in the microstrains resulting in a decrease in the size of coherent domains [33]. Besides, it is reported that the combination of two different SPD methods can lead to a higher thermal stability [34], an increase in high-angle grain boundaries [35], a decrease in the heterogeneity of grain distribution [36], compared with ECAP deformation and/or rolling solely. According to Fig. 9, the changes in the flow stress as a function of ductility are correlated to the microstructural evolutions. It can be concluded that the shift in the elongation is due to the severe plastic strain. Indeed, the peak stress of CR/ECAP $+\mathrm{CR}$ is always less than that of as-received case. The changes in the ductility and flow stress can be attributed to the decrease in the grain size [20]. In accordance with the past works [37-39], the stress level is reduced with decreasing the strain rate. According to Zener-Hollomon parameter $(Z)$ that is most likely because the lower strain rates and/or higher temperatures can provide, respectively, longer time and higher mobility for dislocation motilities. Consequently, this can result in promoting the softening, as shown in Fig. 9.

\subsection{Effects of the Strain Rate and the Temperature on Hot Formability}

\subsubsection{Hot Tensile Ductility}

As shown in Figs. 6 and 7, with increasing the temperature, the maximum in elongation shifted to higher strain rates, especially at $500{ }^{\circ} \mathrm{C}$. The early results suggest that the high-strain-rate superplasticity (HSRS) cannot be easily achieved in materials [4]. However, it is now well established that some UFG Al alloys fabricated by SPD technique exhibit low-temperature superplasticity (LTS) or high-strain-rate superplasticity. In the UFGed Al alloys fabricated by SPD, the HSRS usually takes place at relatively higher temperatures compared to LTS. This indicates that rapid-diffusion-controlled processes are responsible for HSRS in these alloys. In such cases, the thermal stability of the microstructure becomes a more important factor in HSRS than in LTS [40]. This trend was observed during the deformation of SPDed alloys [41]. Thus, these results demonstrate the potential of the SPDed 6061 alloy for achieving high-strain-rate formability. Referring to Fig. 7, it can be concluded that the effect of the temperature on flow stress is more pronounced than that of strain rate. In other words, the hot ductility of this alloy is mostly sensitive to the temperature rather than to the strain rate.

\subsubsection{The Zener-Hollomon Parameter}

The Arrhenius type equation, Eq. (1), is widely used to describe the hot deformation behavior of alloys during hot shear [42, 43], hot compression [44-46] and hot tension [47-49]:

$\dot{\varepsilon}=A[\sin h(\alpha \sigma)]^{n} \exp (-Q / R T)$.

where $\dot{\varepsilon}$ is the strain rate $\left(\mathrm{s}^{-1}\right), R$ the universal gas constant (8.314 $\mathrm{J} \mathrm{mol}^{-1} \mathrm{~K}^{-1}$ ), $T$ the absolute temperature $(\mathrm{K}), Q$ the activation energy related to the deformation mechanisms occurring during hot forming $\left(\mathrm{J} \mathrm{mol}^{-1}\right), \sigma$ the peak stress (MPa), while $A, \alpha$ and $n$ are the material constants. Besides, the interaction of the temperature and the strain rate during the hot deformation of materials can be expressed by the Zener-Hollomon parameter as follows:

$Z=\dot{\varepsilon} \exp (Q / R T)=A[\sin h(\alpha \sigma)]^{n}$.

Figure 10 illustrates the flow chart used to calculate the values of $n, \alpha, Q$ and $A$. The amounts of $n$ and $\beta$ can be obtained from the line slope of $\ln \dot{\varepsilon}-\ln \sigma$ and $\ln \dot{\varepsilon}-\sigma$ plots, respectively. The amount of $\alpha$ can be computed from $n$ and $\beta$ as, $\alpha=\beta / n=5.3 \times 10^{-3} \mathrm{MPa}^{-1}$. As for the amount of $Q$, it is derived from the line slope of $\ln \dot{\varepsilon}-\ln [\sin h(\alpha \sigma)]$ and $\ln [\sin h(\alpha \sigma)]-T^{-1} \times 10^{-3}$ plots. The average amount of activation energy was obtained $196.835 \mathrm{~kJ} / \mathrm{mol}$ here. Then, the $Z$ amounts can be calculated by substituting the strain rates, the temperatures and the activation energy into Eq. (4). Referring to Fig. 10, by plotting $\ln Z-\ln [\sin h(\alpha \sigma)]$, the amount of $A$ can be computed as $6.26 \times 10^{15} \mathrm{~s}^{-1}$. Finally, by substituting the values of $n, A$ and $Q$ into Eqs. (1) and (2), the new models for the hot deformation of SPDed AA6061 alloy can be developed. These are as follows: 


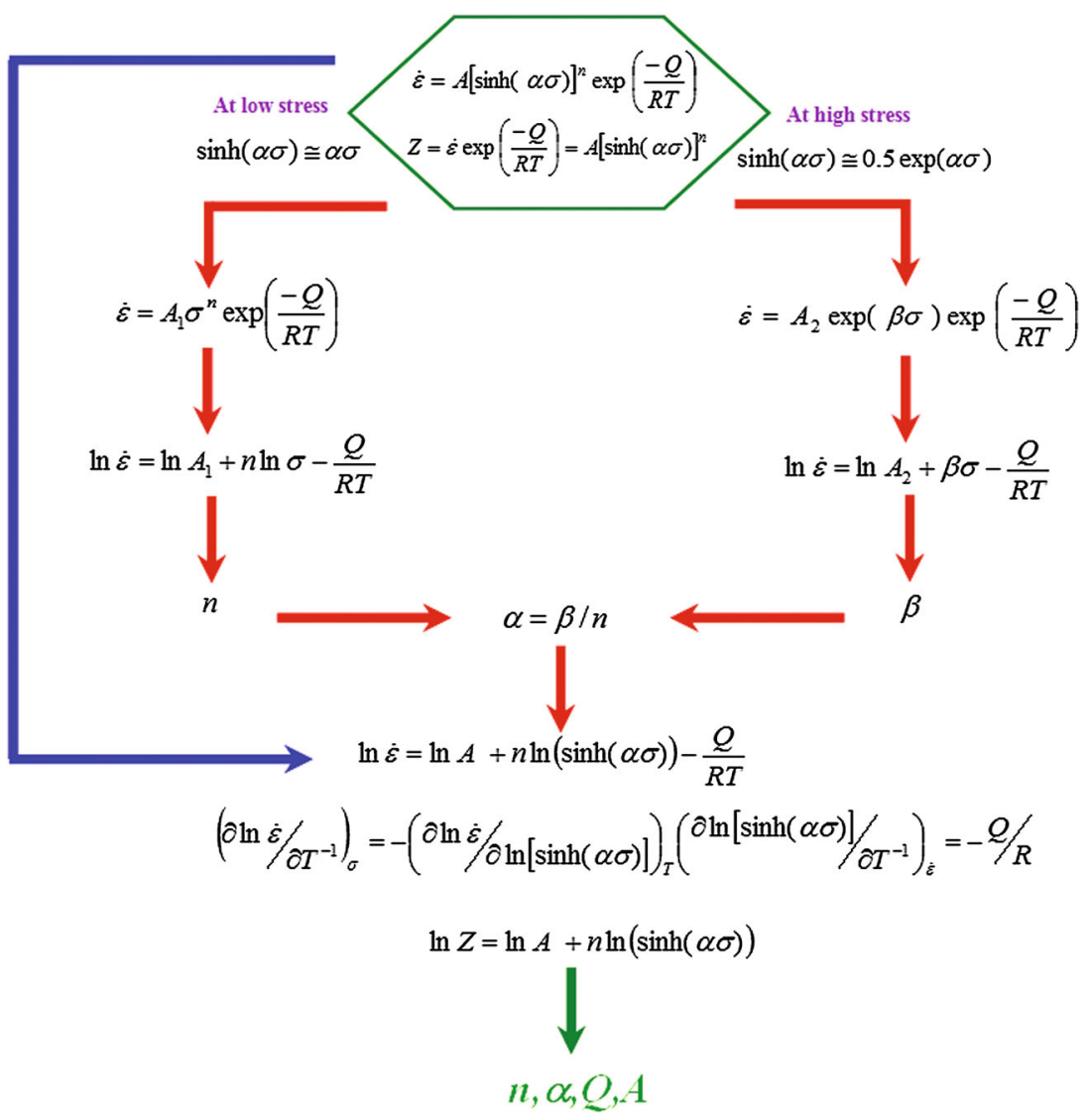

Fig. 10 Flow diagram of constitutive equation
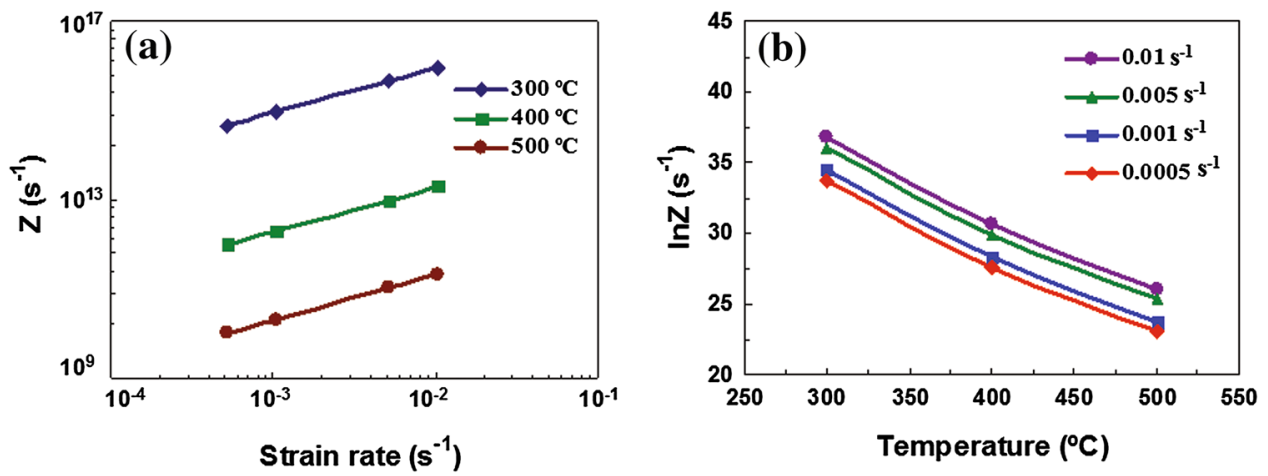

Fig. 11 Variation of the Zener-Hollomon parameter with strain rate a, temperature b

$\dot{\varepsilon}=6.26 \times 10^{15}\left[\sin h\left(5.3 \times 10^{-3} \sigma\right)\right]^{5.06} \exp \left(\frac{196,835}{R T}\right)$.

$Z=\dot{\varepsilon} \exp \left(\frac{196,835}{R T}\right)$

$=6.26 \times 10^{15}\left[\sin h\left(5.3 \times 10^{-3} \sigma\right)\right]^{5.06}$.

The changes in the Zener-Hollomon parameter $(Z)$ with the strain rate and the temperature are shown in Fig. 11. According to this figure, the $Z$ parameter increases with increasing the strain rate and decreasing the deformation temperature. Besides, according to Fig. 11, the effect of the temperature on the Zener-Hollomon parameter seems to be greater than the effect of strain rate.

\subsection{Effect of the Size Sample on Hot Ductility}

According to Fig. 8, the uniform deformation of the samples, occurred before the localized necking, is almost independent of the gauge-length size. By contrast, the non- 
Table 4 A comparison of the maximum elongation of SPD-processed AA6061

\begin{tabular}{|c|c|c|c|c|c|c|c|c|}
\hline Method & $\varepsilon$ & $\begin{array}{l}T \\
\left({ }^{\circ} \mathrm{C}\right)\end{array}$ & $l(\mathrm{~mm})$ & $\mathrm{A}\left(\mathrm{mm}^{2}\right)$ & $l / A^{1 / 2}$ & $\begin{array}{l}T \\
\left({ }^{\circ} \mathrm{C}\right)\end{array}$ & $\dot{\varepsilon}\left(\mathrm{s}^{-1}\right)$ & $\mathrm{El}(\%)$ \\
\hline \multirow[t]{3}{*}{ High-ratio differential speed rolling [20] } & \multirow[t]{3}{*}{1.2} & \multirow[t]{3}{*}{150} & \multirow[t]{3}{*}{5} & \multirow[t]{3}{*}{-} & \multirow[t]{3}{*}{-} & 220 & $1.4 \times 10^{-4}$ & 175 \\
\hline & & & & & & 250 & $9.15 \times 10^{-4}$ & 185 \\
\hline & & & & & & 280 & $9.15 \times 10^{-4}$ & 160 \\
\hline $\operatorname{ECAP}(12 p)+$ peak age $\left(100^{\circ} \mathrm{C}+48 \mathrm{~h}\right)[24]$ & \multirow[t]{3}{*}{12} & \multirow[t]{3}{*}{125} & \multirow[t]{3}{*}{5} & \multirow[t]{3}{*}{8} & \multirow[t]{3}{*}{1.77} & 250 & $1.7 \times 10^{-4}$ & 155 \\
\hline $\begin{array}{l}\mathrm{ECAP}(12 \mathrm{p})+\text { peak age }\left(100{ }^{\circ} \mathrm{C}+48 \mathrm{~h}\right) / \\
\text { without aging }\end{array}$ & & & & & & 540 & $3 \times 10^{-4}$ & 280 \\
\hline $\begin{array}{l}\operatorname{ECAP}(12 p)+\text { peak age }\left(100{ }^{\circ} \mathrm{C}+48 \mathrm{~h}\right) / \\
\text { without aging }\end{array}$ & & & & & & 540 & $1 \times 10^{-3}$ & 260 \\
\hline \multirow[t]{3}{*}{ ECAP (8p) [22] } & \multirow[t]{3}{*}{8} & \multirow[t]{3}{*}{-} & \multirow[t]{3}{*}{5} & \multirow[t]{3}{*}{8} & \multirow[t]{3}{*}{1.77} & 200 & $1 \times 10^{-3}$ & 55 \\
\hline & & & & & & 250 & $1 \times 10^{-3}$ & 100 \\
\hline & & & & & & 280 & $1 \times 10^{-3}$ & 85 \\
\hline ECAP (8p) [17] & 8 & $\begin{array}{l}300(6 \mathrm{p})+ \\
150(2 \mathrm{p})\end{array}$ & 4 & 0.4 & 6.32 & 300 & $1 \times 10^{-4}$ & 150 \\
\hline \multirow[t]{2}{*}{ ECAP $(1 p)+$ rolling (this study) } & \multirow[t]{2}{*}{3.02} & \multirow[t]{2}{*}{$\mathrm{RT}$} & \multirow[t]{2}{*}{5} & \multirow[t]{2}{*}{6} & \multirow[t]{2}{*}{2.04} & 400 & $1 \times 10^{-3}$ & 172 \\
\hline & & & & & & 500 & $1 \times 10^{-3}$ & 208 \\
\hline \multirow[t]{2}{*}{ ECAP $(2 p)+$ rolling (this study) } & \multirow[t]{2}{*}{3.8} & \multirow[t]{2}{*}{ RT } & \multirow[t]{2}{*}{31} & \multirow[t]{2}{*}{6} & \multirow[t]{2}{*}{10.33} & 400 & $1 \times 10^{-3}$ & 74 \\
\hline & & & & & & 500 & $1 \times 10^{-3}$ & 85 \\
\hline
\end{tabular}

$\varepsilon$ strain; $\dot{\varepsilon}$ strain rate; $A$ the initial cross section; $l$ the gauge length; $E l$ elongation to failure

uniform deformation (post-necking) is very strongly affected by the sample size. The extent of the uniform elongation depends on the material characteristics (e.g., $n$ ) as well as on the effect of the specimen size and the shape on the development of the neck region [50, 51]. According to ASTM standards [12, 13], the specimen dimension can influence tensile test results. For cylindrical or rectangular specimens, changing the specimen size generally has negligible effects on the yield and tensile strength but can influence the elongation. According to Barba's law [51] $e_{\mathrm{f}}=\beta\left(A^{1 / 2} / l\right)+e_{\mathrm{u}}\left(e_{\mathrm{f}}\right.$ is the elongation to failure, $\beta$ is a coefficient of proportionality, $A$ is the initial cross section, $l$ is the gauge length and $e_{\mathrm{u}}$ is the uniform elongation), the measured elongation to failure depends on the gauge length of the specimen and the dimension of its cross section. It can be drawn that the similar specimen in geometry develops a similar necked region in geometry [50, 51]. Regarding the effects of the gauge length and elongation measurements in different studies (Table 4), it is complicated because of the use of varied gauge lengths and the cross sections. Therefore, it suggests that the following ratio, i.e., $l / A^{1 / 2}$ can be a controlling factor $[12,13]$. According to Fig. 8 and Table 4, it is readily seen that, for all strain rates, the amount of the elongation increases as this ratio increases. This implies that such a significant increase in hot ductility cannot be achieved when larger tensile samples are used. For example, the elongation of the heavily deformed specimens increased 2.32 times (from 74 to 172 ,) as the mentioned ratio was increased 5.06 times (from 2.04 to 10.33). At the room temperature, an increase in the total elongation was observed for a Ti alloy when the gauge length smaller than $10 \mathrm{~mm}$ was used [52]. Also, Zhao et al. [53] showed that the elongation to failure, post-necking elongation and the strain hardening rate all increased with decreasing the gage length or increasing the thickness of specimens. The thickness influenced the necking geometry, whereas the effect of the gauge length originated from the strain distribution. According to Fig. 8 and Table 4, it is worth mentioning that the effect of the applied strain (one pass or two passes by ECAP) on the elongation is less pronounced comparing to the aforementioned ratio. The samples subjected to two passes of ECAP plus cold rolling exhibited better formability comparing to those subjected to only one pass of ECAP (Fig. 9). However, the effect of the sample size on the hot ductility was higher than the applied SPD. These findings suggest that the hot ductility of the severely deformed workpiece is sensitive to the change of the sample size.

\section{Conclusions}

The effect of ECAP plus cold rolling on the hot ductility of SPDed AA6061 was studied. According to the results of the hot tensile testing, the effects of the microstructural evolution, thermomechanical parameters (temperature and strain rate) and specimen size on the ductility were significant. According to the XRD patterns and TEM analyses, the increase in the hot ductility can be attributed to the 
decrease in the grain/subgrain size. The constitutive equations were developed to model the hot deformation behavior of the SPDed AA6061 and can be used to analyze and study the hot ductility of SPDed AA6061. The changes in the Zener-Hollomon parameter $(Z)$ were dependent on the temperature and the strain rate. These findings suggest that, in addition to the effects of sample size, the hot ductility and $Z$ amount of the severely deformed AA6061 is more sensitive to the changes in testing temperature than the strain rate. Decreasing the ratio of $l / A^{1 / 2}$ is accompanied by an increase in the elongation to failure. However, the sample size exhibited no effect on the uniform elongation.

Acknowledgments The authors thank to Mr. S. A. Motaei and Mr. Haghani for running the ECAP and rolling system.

\section{References}

[1] W.J. Kim, J.Y. Wang, S.O. Choi, H.J. Choi, H.T. Sohn, Mater. Sci. Eng. A 520, 23 (2009)

[2] Y.T. Chen, D.A. Wang, J.Y. Uan, T.H. Hsieh, T.C. Tsai, Mater. Sci. Eng. A 551, 296 (2012)

[3] N.D. Stepanov, A.V. Kuznetsov, G.A. Salishchev, G.I. Raab, R.Z. Valiev, Mater. Sci. Eng. A 554, 105 (2012)

[4] T.G. Langdon, Mech. Mater. 67, 2 (2013)

[5] M. Kawasaki, R.B. Figueiredo, C. Xu, T.G. Langdon, Metal. Mater. Trans. A 33, 1891 (2007)

[6] W.A. Soer, A.R. Chezan, JThM De Hosson, Acta Mater. 54, 3827 (2006)

[7] R. Mahmudi, R. Alizadeh, A.R. Geranmayeh, Scr. Mater. 64, $521(2011)$

[8] R.B. Figueiredo, M. Kawasaki, C. Xu, T.G. Langdon, Mater. Sci. Eng. A 493, 104 (2008)

[9] E. Avtokratova, O. Sitdikov, M. Markushev, R. Mulyukov, Mater. Sci. Eng. A 538, 386 (2012)

[10] B. Verlinden, J. Driver, I. Samajdar, R. D. Doherty, ThermoMechanical Processing of Metallic Materials, 1st edn, ed. by R.W. Cahn, Pergamon Materials Series (Elsevier, Amsterdam, 2007), p. 120

[11] G. Simons, Ch. Weippert, J. Dual, J. Villain, Mater. Sci. Eng. A 416, 290 (2006)

[12] E8/E8M-13a, Standard Test Methods for Tension Testing of Metallic Materials, Annual Book of ASTM Standards (2013)

[13] B557/557M-10, Standard Test Methods for Tension Testing Wrought and Cast Aluminum and Magnesium Alloy Products (Metric), Annual Book of ASTM Standards, (2010)

[14] E21/E21M-09, Standard Test Methods for Elevated Temperature Tension Tests of Metallic Materials, Annual Book of ASTM Standards, (2009)

[15] R. Kaibyshev, F. Musin, D. Gromov, T.G. Nieh, D.R. Lesuer, Scr. Mater. 47, 569 (2002)

[16] R. Kaibyshev, F. Musin, D. Gromov, T.G. Nieh, D.R. Lesuer, Mater. Trans. 43, 2392 (2002)

[17] R.K. Islamgaliev, N.F. Yunusova, M.A. Nikitina, K.M. Nesterov, Rev. Adv. Mater. Sci. 25, 241 (2010)

[18] L.P. Troeger, E.A. Starke Jr, Mater. Sci. Eng. A 277, 102 (2000)

[19] L.P. Troeger, E.A. Starke Jr, Mater. Sci. Eng. A 293, 19 (2000)

[20] W.J. Kim, S.J. Yoo, Scr. Mater. 61, 125 (2009)
[21] B.P. Kashyap, P.D. Hodgson, Y. Estrin, I. Timokhina, M.R. Barnett, I. Sabirov, Metal. Mater. Trans. A 40, 3294 (2009)

[22] W.J. Kim, Y.K. Sa, H.K. Kim, U.S. Yoon, Mater. Sci. Eng. A 487, 360 (2008)

[23] B. Cherukuri, T.S. Nedkova, R. Srinivasan, Mater. Sci. Eng. A 410-411, 394 (2005)

[24] W.J. Kim, J.K. Kim, T.Y. Park, S.I. Hong, D.I. Kim, Y.S. Kim, J.D. Lee, Metal. Mater. Trans. A 33, 3155 (2002)

[25] ASM Handbook, Nonferrous Alloys and Special-Purpose Materials, vol. 2, 9nd edn. (ASM International, Materials Park, 1990), p. 401

[26] E. Tan, A.A. Kibar, C.H. Gür, Mater. Char. 62, 391 (2011)

[27] B. Gopi, N.N. Krishna, K. Venkateswarlu, K. Sivaprasad, World Acad. Sci. Eng. Technol. 61, 731 (2012)

[28] A.P. Zhilyaev, T.G. Langdon, Prog. Mater Sci. 53, 893 (2008)

[29] M. Weiss, A.S. Taylor, P.D. Hodgson, N. Stanford, Acta Mater. 61, 5278 (2013)

[30] V.V. Stolyarov, Y.T. Zhu, I.V. Alexandrov, T.C. Lowe, R.Z. Valiev, Mater. Sci. Eng. A 343, 43 (2003)

[31] L. Nan, A. Zhinan, L. Wenjun, W. Yandong, Acta Metall. Sin. (Engl. Lett.) 26, 663 (2013)

[32[ D.V. Gunderov, A.V. Polyakov, I.P. Semenova, G.I. Raab, A.A. Churakova, E.I. Gimaltdinova, I. Sabirov, J. Segurado, V.D. Sitdikov, I.V. Alexandrov, N.A. Enikeev, R.Z. Valiev, Mater. Sci. Eng. A 562, 128 (2013)

[33] Sh. Ranjbar Bahadori, K. Dehghani, F. Bakhshandeh, Mater. Sci. Eng. A 588, 260 (2013)

[34] V.V. Stolyarov, L. Zeipper, B. Mingler, M. Zehetbauer, Mater. Sci. Eng. A 476, 98 (2008)

[35] M.S. Rao, U. Chakkingal, T. Raghu, Trans. Ind. Inst. Met. 66, 357 (2013)

[36] Sh. Ranjbar Bahadori, K. Dehghani, F. Bakhshandeh, Mater. Sci. Eng. A 583, 36 (2013)

[37] F. Montheillet, J.J. Jonas, Encycl. Appl. Phys. 16, 205 (1996)

[38] S. Sakui, T. Sakai, K. Takeishi, Trans. Iron Steel Inst. Jpn. 17, 718 (1977)

[39] K. Dehghani, A.A. Khamei, Mater. Sci. Eng. A 527, 684 (2010)

[40] D.H. Shin, D.Y. Hwang, Y.J. Oh, K.T. Park, Metal. Mater. Trans. A 35, 825 (2004)

[41] R.B. Figueiredo, M. Kawasaki, Ch. Xu, T.G. Langdon, Mater. Sci. Eng. A 493, 104 (2008)

[42] M. Karami, R. Mahmudi, Mater. Sci. Eng. A 576, 156 (2013)

[43] M. Karami, R. Mahmudi, Mater. Lett. 81, 235 (2012)

[44] H. Farnoush, A. Momeni, K. Dehghani, M.J. Aghazadeh, H. Keshmiri, Mater. Des. 31, 220 (2010)

[45] A. Momeni, K. Dehghani, X.X. Zhang, J. Mater. Sci. 47, 2966 (2012)

[46] M. Wang, P. Jin, J. Wang, L. Han, Ch. Cui, Acta Metall. Sin. (Engl. Lett.) 27, 63 (2014)

[47] Y.C. Lin, Y. Ding, M.S. Chen, J. Deng, Mater. Des. 52, 118 (2013)

[48] B. Meng, M. Wan, X. Wu, Y. Zhou, Ch. Chang, Int. J. Ref. Met. Mater. 45, 41 (2014)

[49] M. Zhou, Y.C. Lin, J. Deng, Y.Q. Jiang, Mater. Des. 59, 141 (2014)

[50] G.E. Dieter, Mechanical Metallurgy, 3rd edn. (McGraw-Hill, New York, 1986), p. 293

[51] ASM Handbook, Mechanical Testing and Evaluation, vol. 8, 4nd edn. (ASM International, Materials Park, 1992), pp. 26-27

[52] A.V. Sergueeva, J. Zhou, B.E. Meacham, D.J. Branagan, Mater. Sci. Eng. A 526, 79 (2009)

[53] Y.H. Zhao, Y.Z. Guo, Q. Wei, A.M. Dangelewicz, C. Xu, Y.T. Zhu, T.G. Langdon, Y.Z. Zhou, E.J. Lavernia, Scr. Mater 59, 627 (2008) 